\title{
ANÁLISE DAS CONSTITUIÇÕES ESTADUAIS BRASILEIRAS E SEU CONTEÚDO QUANTO AOS DIREITOS DA PESSOA COM DEFICIÊNCIA
}

\section{ANALYSIS OF BRAZILIAN STATES CONSTITUTIONS AND THEIR CONTSENT ON THE RIGHT OF THE PEOPLE WITH DISABILITY}

\author{
Rafaela Smania Mendes Blauth ${ }^{1}$ \\ Reginaldo de Souza Vieira ${ }^{2}$
}

RESUMO: A Constituição Federal de 1988 designou como competência comum da União, dos Estados, do Distrito Federal e dos Municípios legislar sobre a proteção e integração social das pessoas com deficiência. Nesse sentido, esta pesquisa tem por objetivo analisar como os Estados brasileiros legislaram sobre a pessoa com deficiência em suas constituições estaduais. Para tanto, buscou-se, a partir do método de pesquisa quantitativa descritiva documental, analisar as constituições estaduais brasileiras a partir de cinco elementos: saúde, educação, trabalho, acessibilidade e lazer.

Palavras chave: Pessoa Com Deficiência, Constituições Estaduais, Constituição Federal, Políticas Públicas, Inclusão Social.

ABSTRACT: The Federal Constitution of 1988 designated as common competence of the Union, States, Federal District and Municipalities to legislate on the protection and social integration of people with disabilities. In this sense, this research aims to analyze how the Brazilian states legislated on the people with disabilities in their state constitutions. In order to do so, it was sought, from the quantitative descriptive method of documentary research, to analyze the constitutions from five elements: health, education, work, accessibility and leisure.

Key words: People with disabilities, State Constitutions, Federal Constitution, Public Policy, Social Inclusion.

\section{INTRODUÇÃO}

\footnotetext{
${ }^{1}$ Mestranda pelo Programa de Pós-Graduação em Direito da Universidade do Extremo Sul Catarinense UNESC. Integrante do Núcleo de Pesquisa em Estado, Política e Direito - NUPED da UNESC. Professora titular na Instituição de Ensino Superior de Criciúma - ESUCRI no curso de Direito e coordenando o grupo de estudos Direito, Estado e Políticas Públicas (GEDEPP/ESUCRI). Advogada. E-mail: rafaelasmania@gmail.com 2 Doutor (2013) e Mestre (2002) em Direito pelo Programa de Pós-graduação em Direito - Mestrado e Doutorado, da Universidade Federal de Santa Catarina. Professor, pesquisador e Coordenador Adjunto do Programa de Pós-Graduação em Direito (PPGD/UNESC). Professor e pesquisador do Programa de PósGraduação em Desenvolvimento Socioeconômico (PPGDS/UNESC). Professor titular da Universidade do Extremo Sul Catarinense, atuando nos cursos de Direito e Odontologia. Coordenador do Núcleo de Estudos em Estado, Política e Direito (NUPED/UNESC) Advogado. E-mail: prof.reginaldovieira@gmail.com 
As garantias legais da pessoa com deficiência estabelecidas pela legislação vigente são resultado de um processo histórico, político, social, bem como da evolução das instituições jurídicas até a ascensão dos direitos sociais.

A Constituição Federal de 1988, nesse sentido, foi um marco jurídico para a institucionalização dos direitos da pessoa com deficiência, uma vez que, além de reconhecêlas como sujeito de direitos e garantias, designou como competência comum da União, dos Estados e do Distrito Federal e Municípios o dever de cuidar da saúde e da assistência pública, proteção e garantia dos direitos das pessoas com deficiência, possibilitando a expansão e cumprimento dos preceitos constitucionais relacionados aos direitos fundamentais e sociais.

A presente pesquisa tem por objetivo geral analisar se e como as Constituições Estaduais Brasileiras desenvolveram os direito das pessoas com deficiência

Para fins de delimitar o estudo as Constituições Estaduais serão analisadas em seu conteúdo quanto a cinco aspectos em referência à pessoa com deficiência: saúde, educação, acessibilidade, trabalho e lazer. Estes elementos foram escolhidos para servir de base desta pesquisa, tendo em vista que estes pesquisadores entendem ser aspectos básicos que devem estar presentes em todas as constituições estaduais no sentido de garantir o mínimo de direitos e garantias da pessoa com deficiência para que estas possam conviver em sociedade.

Assim, esta pesquisa científica será realizada pelo método dedutivo, procedimento quantitativo descritivo, a partir das técnicas de pesquisa documental e bibliográfica, pelas categorias estabelecidas: saúde, educação, acessibilidade, trabalho e lazer.

Em um primeiro momento, analisar-se-á como a Constituição Federal de 1988 reconheceu a pessoa com deficiência e quais as suas principais garantias e direitos estabelecidos pela Carta Magna. Posteriormente, serão estudadas as cinco categorias selecionadas para compor esta pesquisa. Por fim, será analisado como as Constituições Estaduais trataram em seus diplomas legaisas cinco categorias sob análise: saúde, educação, acessibilidade, trabalho e lazer. 
A Constituição República Federativa do Brasil de 1988 foi fundamental para o reconhecimento dos direitos conferidos às pessoas com deficiência. Diferente das constitituições brasileiras antecedentes que pouco dispuseram sobre a pessoa com deficiência, esta determinou a obrigação do Estado em garantir que a pessoa com deficiência possa usufruir amplamente de uma vida digna em todos os seus aspectos, com as mesmas oportunidades disponíveis a qualquer outro cidadão brasileiro (BRASIL, 1988).

Isso se deu em razão do caráter social da Constituição Federal de 1988, que estabeleceu o Estado Democrático de Direito sob os fundamentos da República elencados pela Constituinte no art. $1^{\circ}$ da Carta Magna, dentre os quais destaca-se a dignidade da pessoa humana (BRASIL, 1988).

Este valor, posto como base para nortear a atuação do Estado em suas atribuições, foi definido por Sarlet (2007) como um complexo de direitos fundamentais intrínsecos à condição de ser humano, que asseguram a proteção da pessoa contra atos degradantes, teno por referência o princípio da dignidade humana.

Assim, em se tratando da pessoa com deficiência, o princípio da dignidade da pessoa humana como fundamento da república, pressupõeque o Estado atue de modo incisivo para garantir a sua não discriminação, diferenciação ou segregação no que se refere à participação da vida em sociedade, promovendo condições existenciais mínimas para estas possam gozar de uma vida digna.

Assim, o Estado tem a obrigação de desenvolver legislações, políticas e programas de inclusão da pessoa com deficiência por meio do acesso à saúde, ao trabalho, à cultura e ao lazer, à educação, à participação na cidade enquanto espaço físico, à cidadania, e tudo aquilo que estiver disponível aos demais cidadãos.

Nesse intento, a CRFB/1988 consagrou algumas garantias e direitos destinados à pessoa com deficiência, buscando, além de estabelecer um padrão mínimo de condições de vida, consagrar parâmetros a serem observados em todas as demais legislações infraconstitucionais.

A Constituição Federal não trabalhou a pessoa com deficiência a partir de um rol de direitos em um único capítulo ou sessão, mas ao longo do texto constituicional é possível observar que houve o estabelecimento de garantias em diversos aspectos. A exemplo disso, cita-se o artigo $7^{\circ}$, inciso XXXI da Constituição Federal, quedesenvolveu a proibição de 
qualquer discriminação da pessoa com deficiência quanto aos salários e critérios de admissão (BRASIL, 1988).

No mesmo sentido, o artigo 37, inciso VIII, estabelece que a lei deve reservar cargos públicos para as pessoas com deficiência, destacando nesses casos, e para os segurados do regime geral da previdência social, a adoção de requisitos e critérios diferenciados para a aposentadoria da pessoa com deficiência, conforme os respectivos artigos 40, §4 $4^{\circ}$, I e 201, $\S 1^{\circ}$. (BRASIL, 1988)

Quanto à assistência social, a Constituição garantiu à pessoa com deficiência a garantia de um salário mínimo mensal à pessoa com deficiência que comprovar não possuir meios de prover sua própria subsistência, conforme a redação do artigo 203, inciso V (BRASIL, 1988).

Em se tratando de educação, preconizou pelo artigo 208 inciso III o atendimento educacional especializado à pessoa com deficiência, especialmente na rede regular de ensino, comprometendo-se a promover programas de assistência integral à saúde da criança e do adolescente, mediante a criação de programas específicos às pessoas com deficiência no sentido de facilitar o acesso ao trabalho, aos bens e serviços coletivos e, sobretudo, buscando a sua inclusão na sociedade por meio da eliminação do preconceito, nos termos do artigo 227, $\S 1$, inciso II (BRASIL, 1988).

Por fim, o texto constitucional também estabeleceu a criação de Lei infraconstitucional para dispor sobre a adaptação de logradouros, edifícios e veículos de transporte coletivos, objetivando o amplo acesso da pessoa com deficiência, conforme art. 227, $\S 2^{\circ}$ e art. 244 (BRASIL, 1988).

Conforme se observa, a CRFB/1988 prescreveu diversos direitos e garantias às pessoas com Deficiência. No entanto, a responsabilidade de dispor sobre garantias e direitos das pessoas com deficiência não é exclusiva da União. Em seu artigo 23 do texto constitucional dispôs que a competência para legislar sobre a saúde, assistência pública, proteção e garantia das pessoas com deficiência foi estendida aos Estados, ao Distrito Federal e aos municípios (BRASIL, 1988).

Assim, considerando a inquietação desta pesquisa, torna-se necessária uma abordagem das categorias de análise que serão utilizadas no estudo. 


\section{CATEgorias PARA ANÁlise dOS DIREITOS DAS PESSOAS COM DEFICIÊNCIA NAS CONSTITUIÇÕES ESTADUAIS}

A Constituição Federal de 1988 determinou como competência concorrente à União, Estados, Distrito Federal e aos Municípios legislar sobre as matérias de proteção e integral social da pessoa com deficiência. Nesse sentido, o presente trabalho busca analisar como as Unidades Federativas propõe em suas Constituiçõe Estaduais esta proteção e integração da pessoa com deficiência.

Para realização desta pesquisa, optou-se analisar as Consitituições Estaduais e seus dispositivos em cinco categorias: saúde, educação, acessibilidade, trabalho e lazer, tendo em vista que a partir destes indicadores é possível avaliar o tratamento das Unidades Federativas em suas constituições com a pessoa com deficiência na promoção de sua integração e proteção social.

\subsection{Direito à Saúde}

A Consitutição Federal de 1988 estabeleceu em seu art. 196 que a saúde, além de ser um direito de todos, é um dever do Estado (BRASIL, 1988). Nesse sentido, garantiu a criação de políticas econômicas e sociais buscando a promoção, proteção e recuperação da saúde dos cidadãos.

A esse aspecto, cumpre destacar que:

“ (...) a saúde deve ser visualizada como um processo em construção, não como algo acabado. Ela é influenciada pelo meio no qual o sujeito humano convive e pelas relações políticas, econômicas e sociais. Como sendo algo em construção/reconstrução, a abrangência de seu significado dependerá dos interesses e das forças sociais envolvidas no processo. Por conseguinte, o espaço saúde se caracteriza como um ambiente onde a cidadania pode e deve ser exercitada, onde as forças sociais que compõe a Sociedade devem atuar para que ela venha representar não apenas uma promessa, mas se concretize em um instrumento de resgate da dignidade do ser humano" (VEIRA, 2013, p. 275).

Ainda sob o entendimento do autor, a Constituição Federal de 1988 foi um divisor de águas para a questão da saúde. Se antes a saúde era tratada como mercadoria, um bem possível de ser conquistado como os demais dentro de uma estrutura capitalista, após a 
Constituição Federal de 1988, a saúde foi elencada não apenas como um direito e um processo, mas como valor e um princípio de caráter de Direito Social (VIEIRA, 2013).

Nesse sentido, no que se refere à saúde da pessoa com deficiência, o Estado precisa garantir que este processo esteja em movimento, em crescente desenvolvimento. Para tanto, é necessário que sejam estabelecidos programas de proteção, incentivo à saúde, fornecimento de remédios, equipamentos, atendimento especializado e tudo mais que for necessário para o cumprimento deste direito social constitucionalmente garantido.

No entanto, zelar pela saúde da pessoa com deficiência não é de competência exclusiva da União. $\mathrm{O}$ art. 23 do texto constitucional elenca como competência concorrente à União, aos Estados, Distrito Federal e Municípios esta responsabilidade, bem como estabelece pelo inciso XII do art. 24 a competência para que estes entes legislem sobre o tema (BRASIL, 1988).

Nesse aspecto, a categoria do direito à saúde irá avaliar, nas constituições estaduais brasileiras, se houve o estabelecimento legal de normas, parâmetros, políticas e programas de acesso da pessoa com deficiência à saúde.

\subsection{Direito À Educação}

A Constituição Federal consagrou o direito à educação como um direito social e incumbiu o Estado de promover e incentivar a educação, visando sempre o desenvolvimento eficaz dos cidadãos, o seu preparo para a cidadania e para o trabalho.

Assim, o direito à educação não se limita a dispor modo pelo qual e como serão repassadas culturas, saberes e valores aos indivíduos, mas é um elemento essencial para o desenvolvimento do Estado Democrático de Direito, tendo em vista seu papel importante na formação e qualificação dos cidadãos para o trabalho e para a vida em sociedade (BRAGA; FEITOSA 2016).

Nesse aspecto e, também sob o princípio da dignidade da pessoa humana, a CRFB/1988 determinou a obrigação do Estado em buscar a concretização do direito à educação às pessoas com deficiência, mediante a garantia de atendimento educacional especializado de preferência, pela rede de ensino regular (BRAGA; FEITOSA, 2016).

O direito à educação da pessoa com deficiência é de grande relevância para que as pessoas com deficiência possam ser não apenas inseridas na sociedade, mas incluídas, 
preparando-as para o trabalho, para o lazer, cultura e para que possam desfrutar do exercício da cidadania.

Para tanto, a Constituição Federal estabeleceu ao artigo 208 que é dever do Estado efetivar o direito à educação da pessoa com deficiência mediante atendimento educacional especializado às pessoas com deficiência, bem como instituiu como competência comum da União, Estados, Distrito Federal e Municípios a promoção da garantia dos direitos da pessoa com deficiência, de modo que é papel tanto da União quanto das unidades federativas a efetivação desses direiros, operando um conjunto de ações e programas governamentais que possibilitem e facilitem o acesso e a permanência das pessoas com deficiência nas redes de ensino (BRASIL, 1988).

Deste modo, a categoria à qual se refere o direito à educação na análise das constituições estaduais, engloba a educação em seus variados aspectos, seja na facilitação de ingresso às redes de ensino, à criação de programas que preparem os professores para se comunicar com os variados tipos de deficiência, além das políticas de apoio à permanência dos estudantes com deficiência em sala de aula e outras medidas destinadas à educação da pessoa com deficiência.

\subsection{Direito ao Lazer}

O lazer pode ser entendido como um conjunto de ocuoações pela qual os indivíduos podem se entregar sem responsabilidades para diversão, recreação, entretenimento e para desenvolver suas capacidades criativas, visto que, ao livrar-se das ocupações rotineiras de trabalho familia e outros compromissos, os indivíduos, tendem a melhorar sua saúde e diminuir os níveis de estresse.

Considerando o seu caráter social, o lazer possui uma característica importante no que se refere aos espaços consagrados como de lazer pelo Poder Público: eles demonstram ser ocupados e divididos conforme os grupos sociais em que a sociedade é dividida (COTOMACCI, 2007).

São muitas as barreiras arquitetônicas que impedem as pessoas com deficiência de livremente percorrer os espaços públicos de lazer. Seja com relação à acessibilidade, ao preconceito, a falta de iniciativa de programas de lazer, este impedimento influencia na falta de integração da pessoa com deficiência nos espaços públicos de lazer. Ou seja, estas muitas 
vezes encontram-se impossibilitades de usufruir dos espaços de lazer na mesma proporção que as pessoas sem deficiência o fazem (COTOMACCI, 2007)

Não se pode, todavia, resumir os momentos de lazer ao gozo dos espaços públicos. Também faz parte do convívio com a sociedade em seu amplo sentido, o acesso aos momentos de lazer em determinados estabelecimentos privados, como por exemplo, a presença em festas, cinemas, teatros, musicais e outros ambientes de recreação são tão necessários na vida da pessoa com deficiência quanto na de qualquer outra pessoa. Esses momentos são importantes pois ocupam a mente o corpo, liberando o estresse de uma rotina muitas vezes tensa, trazendo qualidade de vida e saúde para os indivíduos. (COTOMACCI, 2007).

Nesse intento, ao tratar do marcador do direito ao lazer, este trabalho irá avaliar a presença de dispositivos nas Constituições Estaduais que tratem sobre facilitação na participação da pessoa com deficiência em momentos de esportes por lazer, cinema, espetáculos, museus, outros segmentos de cultura e de incentivo ao lazer da pessoa com deficiência em seus diversos aspectos.

\subsection{Do Direito ao Trabalho}

A experiência do trabalho possui a função social de trazer sentido à vida dos invidivíduos enquanto cidadãos parte de uma sociedade. Segundo Tomazini:

Todo homem é em potencial um trabalhador. O trabalho se constitui na atividade vital do homem. É a fonte de objetivação do ser humano e através dele os homens transformam o mundo e se transformam, enquanto sujeitos sociais. [...] $\mathrm{O}$ trabalho define a condição humana e situa a pessoa no complexo conjunto das representações sociais, definindo a posição do homem nas relações de produção, nas relações sociais e na sociedade como um todo(1996, p. 45).

Nesse sentido, não se pode ignorar as capacidades das pessoas com deficiência e se fixar somente em suas limitações ou restrições. É preciso que haja o encorajamento que seus potenciais podem ser desenvolvidos e melhorados, e que estas podem contribuir para crescimento, transformação e aprimoramento de empresas ou no setor público, em caso de cargos públicos (RESENDE, 2014).

\footnotetext{
Rev. de Direito Sociais e Políticas Públicas | e-ISSN: 2525-9881 | Goiânia| v. 5 | n. 1 | p. 119-140| Jan/Jun. 2019
} 
Incluir a pessoa com deficiência no trabalho e prorporcionar esta experiência por meio de incentivos é contribuir para sua realização emocional e pessoal. A participação na vida ativida por meio de um emprego contribui para a inclusão e interação da pessoa com deficiênia e os demais cidadãos, ampliando seus conhecimentos sobre o mundo, fora dos limites de suas casas ou dos ambientes hospitalares. O trabalho, nesse sentido, é capaz de resgatar a autoconfiança e a autoestima da pessoa com deficiência (RESENDE, 2014).

Assim, é necessário que o Estado atue incentivando a contratação de pessoas com deficiência, desenvolvendo políticas de incentivo ao desenvolvimento dos seus potenciais e na execução de programas que despertem o interesse das empresas e que facilitem o ingresso da pessoa com deficiência no mercado de trabalho para que estas também possam desfrutar da experiência do trabalho como os demais cidadãos.

\subsection{Do Direito à Acessibilidade}

Para que seja possível a inclusão das pessoas com deficiência é necessário, sobretudo, que haja disposições legais que garantam e efetivem a sua autonomia, sua independência e capacidade de realizar os atos da vida comuns a todos os cidadãos. Para tanto, efetivação da acessibilidade é essencial (LARAIA, 2009).

Romeu Kazumi Sassaki (2005), conceitua a acessibilidade em seis aspectos: arquitetônica, comunicacional, metodológica, instrumental, programática e atitudinais:

Acessibilidade arquitetônica, sem barreiras ambientais físicas em todos os recintos internos e externos da escola e nos transportes coletivos; Acessibilidade comunicacional, sem barreiras na comunicação interpessoal (face a face, língua de sinais, linguagem corporal, linguagem gestual etc.), na comunicação escrita: jornal, revista, livro, carta, apostila etc., incluindo textos em Braille, textos com letras ampliadas para quem tem baixa visão, notebook e outras tecnologias assistivas para comunicar e na comunicação virtual, acessibilidadevirtual);

Acessibilidade metodológica, sem barreiras nos métodos e técnicas de estudo (adaptações curriculares, aulas baseadas nas inteligências múltiplas, uso de todos os estilos de aprendizagem, participação do todo de cada aluno, novo conceito de avaliação de aprendizagem, novo conceito de educação, novo conceito de logística didática etc), de ação comunitária (metodologia social, cultural, artística etc. baseada em participação ativa) e de educação dos filhos (novos métodos e técnicas nas relações familiares etc.); Acessibilidade instrumental, sem barreiras nos instrumentos e 
utensílios de estudo (lápis, caneta, transferidor, régua, teclado de computador, materiais pedagógicos), de atividades da vida diária (tecnologia assistiva para comunicar, fazer a higiene pessoal, vestir, comer, andar, tomar banho etc.) e de lazer, esporte e recreação: dispositivos que atendam às limitações sensoriais, físicas e mentais,etc.; Acessibilidade programática; sem barreiras invisíveis embutidas em políticas públicas (leis, decretos, portarias, resoluções, medidas provisórias etc.), em regulamentos (institucionais, escolares, empresariais, comunitários etc.) e em normas de um geral;

Acessibilidade atitudinal, por meio de programas e práticas de sensibilização e de conscientização das pessoas em geral e da convivência na diversidade humana resultando em quebra de preconceitos, estigmas, estereótipos e discriminações. (SASSAKI, 2005, p. 10-11).

Nesse sentido, a acessibilidade tem como objetivo proporcionar autonomia e mobilidade às pessoas com deficiência, buscando eliminar qualquer barreira que impeça a pessoa com deficiência de usufruir dos mesmos direitos de qualquer cidadão. Sejam essas barreiras nos transportes, urbanísticas, nas comunicações, nos comportamentos ou ainda na tecnologia (LARAIA, 2009).

Para a eficácia da promoção da proteção e integração social da pessoa com deficiência, se faz necessária a adequação dos acesssos e diminuição de barreiras que possibilita o direito de ir e vir dos indivíduos. Sem acessibilidade, a pessoa com deficiência poderia ter incentivos no que se refere ao trabalho, ao lazer, à educação, mas não poderia sequer usufruir de tais direitos.

A Constituição Federal de 1988 estabeleceu a garantia da acessibilidade da pessoa com deficiência por meio de diversas diretrizes. A exemplo disso, cita-se a obrigação de adaptação de logradouros, edifícios de uso público e aos veículos de transporte coletivos (BRASIL, 1988).

Deste modo, considerando a competência concorrente entre a União e as Unidades Federativas no sentido de proteger a pessoa com deficiência e promover sua inegração social, o presente trabalho irá avaliar se as Constituições Estaduais possuem em seus textos legais o tema da acessibilidade às pessoas com deficiência quanto à diminuição e eliminação das barreiras existentes.

\section{DOS RESUltados: DA ANÁLISE DAS CATEgorias ELEGIDAS NAS CONSTITUIÇÕES DOS ESTADOS BRASILEIROS}

Rev. de Direito Sociais e Políticas Públicas | e-ISSN: 2525-9881 | Goiânia| v. 5 | n. 1 | p. 119-140| Jan/Jun. 2019 
Coube ao Poder Constituinte determinar que as Assembléias Legislativas de cada estado brasileiro elaborasse sua Constituição Estadual, observando os princípios, competências e garantias constitucionais positivadas na Carta Magna de 1988. Além disso, designou aos Estados, a competência comum e concorrente de cuidar e legislar sobre a proteção e integração social da pessoa com deficiência (BRASIL, 1988). Este trabalho se propôs, nesse sentido, a averiguar como as constituições estaduais tem disciplinados os direitos das pessoas com deficiência.

Foram consultadas todas as constituições das 26 unidades federativas do País, pelas quais se pode obter os resultados conforme tabelas e gráficos abaixo:

\begin{tabular}{|c|c|c|c|c|c|c|c|c|c|c|c|c|}
\hline Categorias & $\mathrm{AC}$ & AL & AM & AP & BA & CE & ES & GO & MA & MG & MT & MS \\
\hline SAÚDE & $\mathbf{x}$ & $\mathbf{x}$ & $\mathbf{x}$ & $\mathbf{x}$ & $\mathbf{x}$ & $\mathbf{x}$ & $\mathbf{x}$ & $\mathbf{x}$ & $\mathbf{x}$ & $\mathbf{x}$ & $\mathbf{x}$ & $\mathbf{x}$ \\
\hline EDUCAÇÃO & $\mathbf{x}$ & $\mathbf{x}$ & $\mathbf{x}$ & $\mathbf{x}$ & $\mathbf{x}$ & $\mathbf{x}$ & $\mathbf{x}$ & $\mathbf{x}$ & $\mathbf{x}$ & $\mathbf{x}$ & $\mathbf{x}$ & $\mathbf{x}$ \\
\hline LAZER & $\mathbf{x}$ & & $\mathbf{x}$ & $\mathbf{x}$ & & & $\mathbf{x}$ & $\mathbf{x}$ & & $\mathbf{x}$ & $\mathbf{x}$ & \\
\hline TRABALHO & $\mathbf{x}$ & $\mathbf{x}$ & $\mathbf{x}$ & $\mathbf{x}$ & $\mathbf{x}$ & $\mathbf{x}$ & $\mathbf{x}$ & $\mathbf{x}$ & & & & $\mathbf{x}$ \\
\hline ACESSIBILIDADE & $\mathbf{x}$ & $\mathbf{x}$ & $\mathbf{x}$ & $\mathbf{x}$ & $\mathbf{x}$ & $\mathbf{x}$ & $\mathbf{x}$ & $\mathbf{x}$ & $\mathbf{x}$ & $\mathbf{x}$ & $\mathbf{x}$ & $\mathbf{x}$ \\
\hline TOTAL & 5 & 4 & 5 & 5 & 4 & 4 & 5 & 5 & 3 & 4 & 4 & 4 \\
\hline
\end{tabular}

Fonte: elaborado pelos(as) autores(as).

\begin{tabular}{|l|l|l|l|l|l|l|l|l|l|l|l|l|l|l|}
\hline Categorias & PA & PB & PR & PE & PI & RJ & RN & RO & RR & RS & SC & SE & SP & TO \\
\hline SAÚDE & $\mathrm{x}$ & $\mathrm{x}$ & $\mathrm{x}$ & $\mathrm{x}$ & $\mathrm{x}$ & $\mathrm{x}$ & $\mathrm{x}$ & $\mathrm{x}$ & $\mathrm{x}$ & $\mathrm{x}$ & $\mathrm{x}$ & $\mathrm{x}$ & $\mathrm{x}$ & $\mathrm{x}$ \\
\hline EDUCAÇÃO & $\mathrm{x}$ & $\mathrm{x}$ & $\mathrm{x}$ & $\mathrm{x}$ & $\mathrm{x}$ & $\mathrm{x}$ & $\mathrm{x}$ & $\mathrm{x}$ & $\mathrm{x}$ & $\mathrm{x}$ & $\mathrm{x}$ & $\mathrm{x}$ & $\mathrm{x}$ & $\mathrm{x}$ \\
\hline LAZER & $\mathrm{x}$ & & $\mathrm{x}$ & $\mathrm{x}$ & & $\mathrm{x}$ & & & & $\mathrm{x}$ & & & $\mathrm{x}$ & $\mathrm{x}$ \\
\hline TRABALHO & $\mathrm{x}$ & $\mathrm{x}$ & & & $\mathrm{x}$ & $\mathrm{x}$ & $\mathrm{x}$ & $\mathrm{x}$ & & & & $\mathrm{x}$ & $\mathrm{x}$ & \\
\hline ACESSIBLIDADE & $\mathrm{x}$ & $\mathrm{x}$ & $\mathrm{x}$ & $\mathrm{x}$ & $\mathrm{x}$ & $\mathrm{x}$ & $\mathrm{x}$ & $\mathrm{x}$ & $\mathrm{x}$ & $\mathrm{x}$ & $\mathrm{x}$ & $\mathrm{x}$ & $\mathrm{x}$ & $\mathrm{x}$ \\
\hline TOTAL & $\mathrm{5}$ & 4 & 4 & 4 & 4 & 5 & 4 & 4 & 3 & 4 & 3 & 4 & 5 & 4 \\
\hline
\end{tabular}

Fonte: elaborado pelos(as) autores(as).

Inicialmente, destaca-se que das 26 constituições estaduais pesquisadas, apenas 8 destas cumpriram com as categorias analisadas. 15 constituições cumpriram 4 dos cinco requisitos e, 3 constituições deixaram de cumprir duas das categorias analisadas. 
Isso signifca que, apenas $31 \%$ das Constituições Estaduais cumpriram com o seu dever constituicional de cuidar e legislar sobre as garantias e direitos das pessoas com deficiência nas categorias analisadas por esta pesquisa, conforme demonstra o gráfico abaixo:

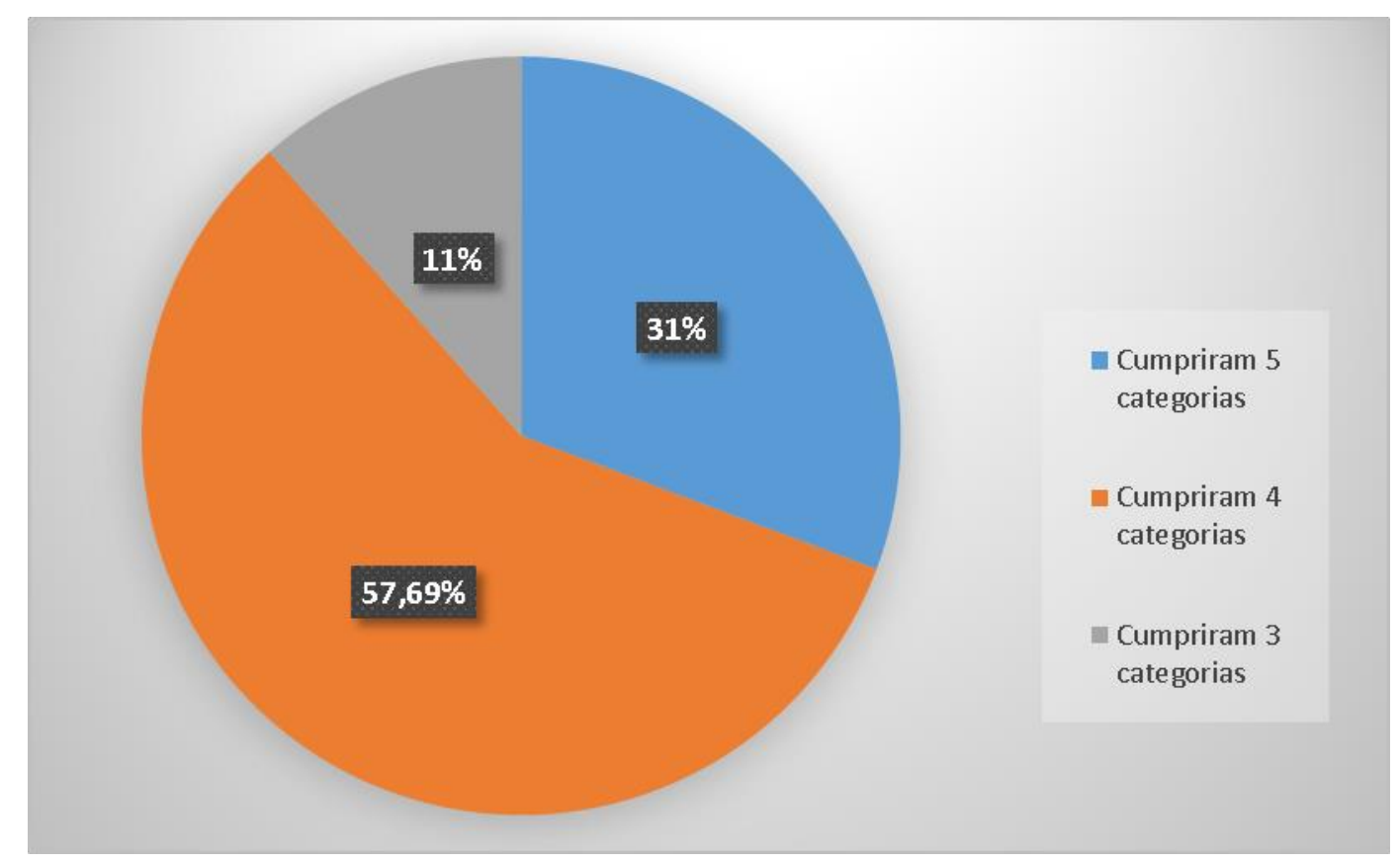

Fonte: elaborado pelos(as) autores(as).

Observou-se também que, das 26 Constituições Estaduais analisadas, todas legislaram sobre educação, acessibilidade e saúde, ao menos em um aspecto, ainda que não tenham desenvolvido com a devida atenção as normas quanto a estes temas.

No entanto, com relação ao lazer e ao trabalho, verificou-se que há constituições estaduais que sequer mencionaram tais garantias e direitos às pessoas com deficiência. Os dados obtidos dão conta que apenas 53,8\% das Constituições Estaduais Brasileiras tratam sobre o direito ao lazer da pessoa com defiência, conforme demonstra o gráfico abaixo: 


\section{CONSTITUIÇÕES ESTADUAIS BRASILEIRAS E OS DIREITOS DAS PESSOAS COM DEFICIÊNCIA}

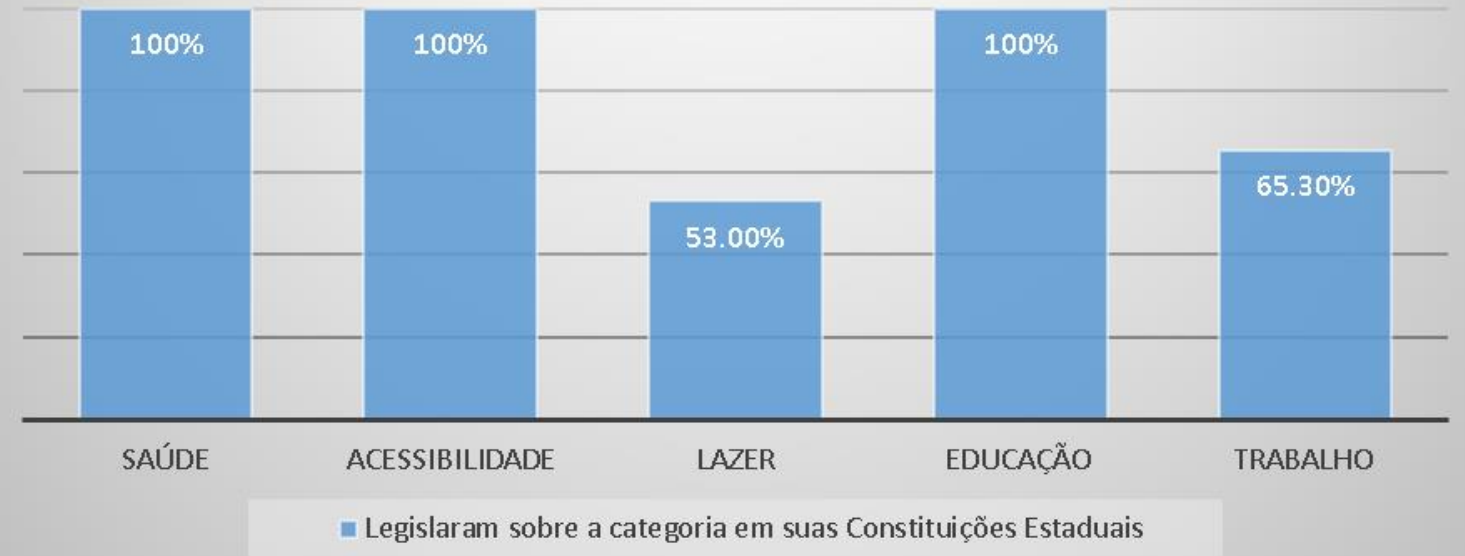

Fonte: elaborado pelos(as) autores(as).

\section{CONSTITUIÇÕES ESTADUAIS E OS DIREITOS DAS PESSOAS COM DEFICIÊNCIA}

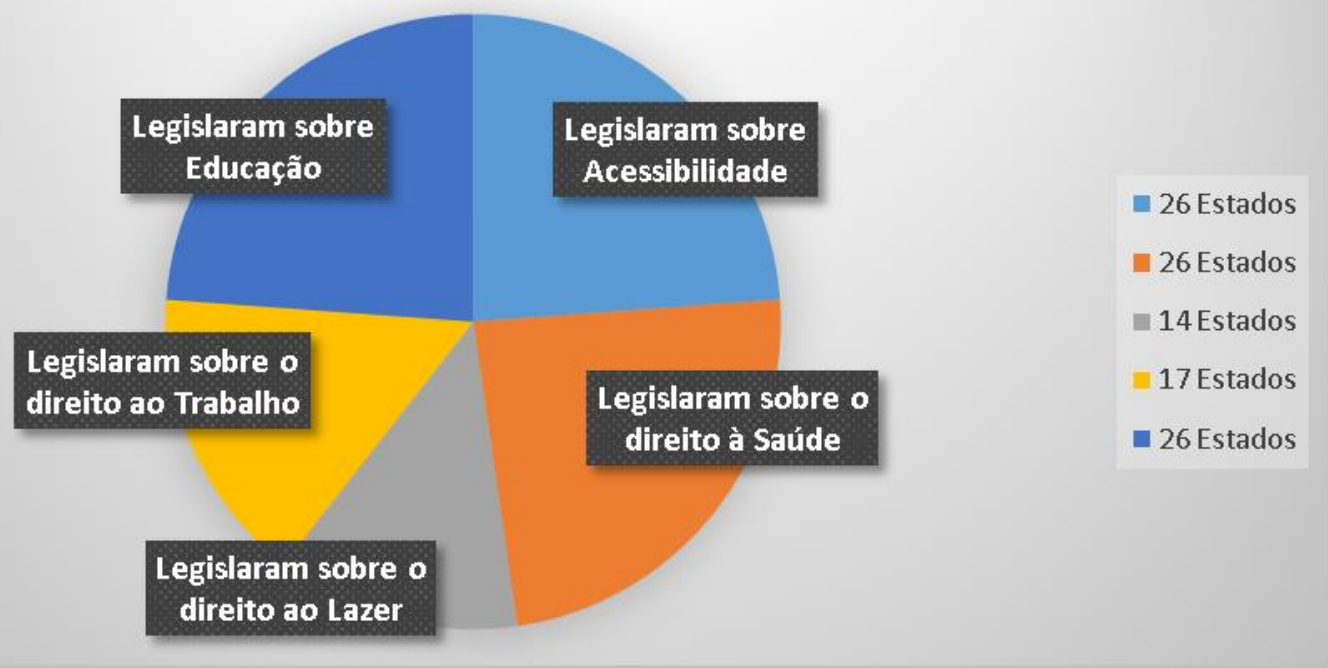

Fonte: elaborado pelos(as) autores(as). 
Verificou-se que 12 estados deixaram de se manifestar quanto ao elemento lazer, sendo que dentre os que legislaram sobre políticas, garantias e direito ao lazer, a maioria estabeleceu relação entre lazer e transporte, deixando de mencionar outras formas de lazer que não a desportiva.

Tal situação é de bastante relevância e demonstra a necessidade de o Poder Público atentar para a criação de políticas públicas de incentivo ao lazer, à convivência por meio de espaços públicos na cidade, como parques, praças e academias públicas adaptadas, bem como o incentivo à participação em shows, espetáculos de música, teatro, dança e outros, que podem ser acessados pelos demais cidadãos.

Com relação a esse aspecto, convém destacar a constituição estadual do estado do Acre, que promoveu o acesso das pessoas com deficiência ao lazer mediante a isenção dos bilhetes de espetáculos, cinemas, teatros, sendo estes privados ou públicos.

Do mesmo modo, a constituição estadual do estado de Goiás tratou de forma bastante específica o direito ao lazer, determinando criação de programas especializados para pessoas com deficiência, visando a melhora da saúde, aumento da produtividade e com fins terapêuticos.

Assim, considerando que a responsabilidade de legislar sobre o lazer das pessoas com deficiência é também um papel dos demais Estados, as constituições estaduais merecem reanalisar seus dispositivos para promover o direito ao lazer, tendo em vista sua importância para a saúde e desenvolvimento das relações sociais, conforme trabalhado em tópico anterior.

Com relação à saúde, verificou-se que embora todos os estados tratem de políticas de saúde determinando o atendimento especializado, alguns estados legislaram além do convencional, como é o caso do Estado de Santa Catarina, que previu a execução de uma política de saúde para garantir a prevenção de doenças, habilitação, reabilitação, comprometendo-se a prover todos os recursos necessários para este fim.

Além disso, a Constituição Estadual de Santa Catarina também determinou que as pessoas com deficiências profundas tenham assistência em instituições em regime de internato ou semi-internato, o que se mostra um cumprimento ao direito de saúde previsto na Constituição Federal, uma vez que o direito de estar sadio e o direito à prevenção de doenças são também inerentes às pessoas com deficiência: 
"O direito à saúde, expresso no art. 196 da CF/88, por ser fundamental à dignidade e à vida da pessoa humana, não pode ser interpretado como mera norma programática que se limita a traçar princípios, objetivos e programas visando à realização dos fins sociais do Estado. Isso frustra e limita o caráter pluralista, dirigente e principiológico da Carta Política, cujo objetivo direciona-se para a concretização de uma justiça social que legitime o Estado Democrático de Direito (art. $3^{\circ}$, da CF/88)" (MARTA; ABUJAMRA, 2010, p. 102)

Assim, constituição estadual que demonstrou preocupação com a saúde, além das garantias já previstas na Constituição Federal, foi a constituição do estado do Ceará. O texto legal determinou a instituição de rede hospitalar e ambulatorial com leitos, espaços e equipamentos gratuitos para as pessoas com deficiência, bem como a distribuição de medicamentos, próteses, órteses e todos os implementos necessários para habilitação e reabilitação da pessoa com deficiência.

No que se refere à educação, todas as constituições dispuseram sobre normas básicas à educação da pessoa com deficiência, como por exemplo, a garantia de ensino especializado para todas as idades. No entanto, poucas constituições foram além das normas gerais. É o que se destaca da Constituição do Amapá, que determinou o ensino de Braile como atendimento educacional especializado às pessoas com deficiência nas escolas públicas e nos estabelecimentos oficiais de ensino.

A educação demonstra-se essencial para a construção de uma vida digna, sendo dever do Estado promover tal direito a todas as pessoas, independente de sua condição, ou condição do meio em que estão inseridas, pois através da educação é possível transformar gerações, construindo uma sociedade mais justa, no entanto, é necessário que haja o reconhecimento das diferenças específicas da pessoa com deficiência a fim de garantir políticas públicas relacionadas ao ensino que que seja adequada a essas características especiais (DORIGON, 2018, p. 9).

Outro diferencial, foi a determinação da Constituição estadual do estado do Espírito Santo, que ampliou o ensino especializado às pessoas com deficiência para o turno da noite e nas unidades hospitalares para aqueles que se encontrarem impossibilitados de participar da escola por período igual ou superior a um ano. Tais medidas certamente foram eficientes para alcancar um número maior de pessoas com deficiência nas redes de ensino. 
Verifica-se que, apesar de todas as constituições abordarem garantias de ensino às pessoas com deficiência, poucas efetivamente trataram de políticas de incentivo e permanência no estudo, na manutenção das salas de aula e dos atendimentos dos demais setores para receber o aluno com deficiência.

Sobre a acessibilidade, todas as unidades federativas trataram em suas constituições a necessidade de adaptação de veículos, logradouros e prédios públicos. No entanto, assim como nos demais aspectos, poucos estados desenvolveram a criação de políticas e programas de inclusão social por meio do acesso. Para Souza (2003, p. 40), acessibilidade é a ocasião necessária para que um fato se concretize:

A acessibilidade é o acesso fácil, qualidade do que é acessível. A falta de acessibilidade no transporte coletivo está associada ás grandes distâncias e longas viagens. O tempo é o momento ou a ocasião apropriada para que um fato se realize. A pouca acessibilidade no transporte está associada ao tempo excessivo de execução de uma viajem. Trata-se da relação tempoespaço (SOUZA, 2003, p. 40).

Nesse aspecto, se demonstra vital ao direito de ir e vir da pessoa com deficiência, que o Estado disponha de meios hábeis para a efetivação do direito à acessibilidade, incluindo-se nesse aspecto, a acessibilidade nos meios de transporte.

Cabe destacar a constituição estadual do Amapá, que determinou a isenção de tarifas para as pessoas com deficiência nos transportes coletivos urbanos, rodoviários e aquaviários, municipais e intermunicipais. Do mesmo modo, as Constituições do Espirito Santo e Rio de Janeiro também determinaram a isenção dos transportes coletivos urbanos.

Curioso ressaltar que no Estado do Rio Grande do Sul houve a previsão de isenção das tarifas de transporte coletivo urbano para a pessoa idosa, mas quando tratado da pessoa com deficiência, este benefício somente é concedido em se tratando de pessoa com deficiência comprovadamente carente.

Conforme se observa, em que pese as constituições tratarem de adaptação dos veículos e dos espaços públicos destinado aos transportes públicos, vários estados do País não conferiram a gratuidade do transporte às pessoas com deficiência, havendo a necessidade de os estados repensarem seus posicionamentos quanto este ponto, considerando que por meio do transporte é que as pessoas com deficiência que moram em bairros mais afastados podem ter acesso à cidade e desfrutar dos mesmos ambientes que qualquer outro cidadão. 
No que tange ao trabalho, 9 estados brasileiros não dispuseram em suas constituições previsões de políticas públicas de incentivo ao ingresso da pessoa com deficiência no mercado de trabalho, sendo o segundo elemento, dentre os cinco, menos legislado pelos Estados.

Dentre os estados que legislaram sobre este elemento, cabe expor o posicionamento do estado da Constituição estadual do Pará, que estabeleceu um interessante requisito para as empresas formalizarem contratos com o Poder Público para obras e aquisição de bens e serviços, mediante licitação ou dispensa na forma da Lei: todas devem possuir, obrigatoriamente, no mínimo $5 \%$ de pessoas com deficiência em seu quadro de funcionários. Tal incentivo sim, mostra a preocupação do Estado com o incentivo à inclusão da pessoa com deficiência no mercado de trabalho.

Outro estado que defendeu o direito ao trabalho da pessoa com deficiência garantindo seu incentivo foi o estado do Acre, que incentivou a inclusão da pessoa com deficiência no mercado de trabalho mediante o incentivo fiscal às empresas que tiverem pessoas com deficiência em seu quadro de funcionários, além de determinar a diminuição da sua jornada de trabalho, comprotetendo-se ainda a incentivar a criação e manutenção de mais empregos com vagas especiais.

Nesse sentido, sabe-se que o trabalho é um elemento essencial para inclusão do ser humano na vida social. Não apenas pela remuneração que lhe permite usufruir de bens acessíveis mediante pagamento, o trabalho possibilita o engajamento do cidadão com a sociedade, através do qual o indivíduo pode conhecer novas pessoas, estar em contato com outras esferas de conhecimento, de relacionamentos interpessoais, além da satisfação pessoal que o trabalho proporciona aos cidadãos.

Assim, verificou-se que a maioria dos Estados Brasileiros não dispuseram em suas Constituições garantias e direitos para inclusão da pessoa com deficiência no mercado de trabalho, sendo este um tema de importância para ser reavaliado.

\section{CONCLUSÃO}


Buscou-se por essa pesquisa avaliar como as Constituições das Unidades Federativas do Brasil contemplaram a pessoa com deficiência em cinco aspectos: saúde, educação, acessibilidade, trabalho e lazer.

A partir do método de pesquisa quantitativo descritivo documental, percebeu-se que todos os $100 \%$ dos estados brasileiros trataram das pessoas com deficiência e discorreram em suas constituições estaduais a questão da acessibilidade, educação e saúde. Todavia, se verificou que a maioria dos estados apenas estabeleceu normas de caráter geral, prevendo a edição de Lei futura ou apenas reproduzindo os dispositivos já contemplados pela Constituição Federal de 1988.

Com relação ao lazer, esta pesquisa pode concluir que apenas 53\% dos estados brasileiros possuem este direito assegurado em suas constituições estaduais no que se refere à pessoa com deficiência.

A questão do trabalho também requer atenção das Unidades Federativas, pois observou-se que ainda há 9 estados brasileiros cujas constituições não prevêem garantias e direitos de falicitação e incentivo do ingresso da pessoa com deficiência no mercado de trabalho. Inclusive, alguns dos estados que legislaram sobre o tema em suas constituições, o fizeram de forma mitigada, apenas prevendo de forma geral o ingresso de pessoas com deficiência no mercado de trabalho, sem, no entanto, dispor sobre facilitações, incentivos às empresas e outras medidas.

Verificou-se, por fim, que apesar de as Constituições Estaduais terem tratado das categorias analisadas por esta pesquisa, poucos estados estabeleceram normas significativas que assegurem o direito da pessoa com deficiência, sem estabelecer padrões mínimos de condutas dos estabelecimentos de ensino, das unidades de saúde, dos locais públicos, das políticas de inclusão no trabalho e também na criação de mecanismos de acesso da pessoa com deficiência ao lazer, sendo de extrema necessidade a reavaliação das Constituições para incorporarem a seus diplomas legais direitos que garantam efetivamente a inclusão social da pessoa com deficiência.

\section{REFERÊNCIAS}

BRAGA, Janine de Carvalho Ferreira; FEITOSA, Gustavo Raposo Pereira. Direito à educação da pessoa com deficiência: transformações normativas e a expansão da 
inclusão no brasil. Disponível em:

https://www.researchgate.net/publication/311779444_DIREITO_A_EDUCACAO_DA_PES SOA_COM_DEFICIENCIA_TRANSFORMACOES_NORMATIVAS_E_A_EXPANSAO_ DA_INCLUSAO_NO_BRASIL. Acesso em 05 set 2018.

BRASIL.

CAVALCANTI, Lana de Souza. Elementos da produção do espaço intraurbano.

Geografia da Cidade: a produção do espaço urbano em Goiânia. Goiânia: Alternativa, 2001.

Constituição da República Federativa do Brasil. Brasília, DF. Disponível em

http://www.planalto.gov.br/ccivil_03/Constituicao/Constituicao.htm Acesso em 04 set 2018

Constituição do Estado do Maranhão. Disponível em:

http://www.stc.ma.gov.br/files/2013/03/CONSTITUI\%C3\%87\%C3\%83O-DO-ESTADO-

DO-MARANH\%C3\%830_atualizada_at\%C3\%A9_emenda69.pdf $>$. Acesso em 04 set 3018

.Constituição do Estado do Amapá. Disponível em:

http://www.al.ap.gov.br/constituicao_estadual_amapa.pdf>. Acesso em 05 set 2018

Constituição do Estado do Rio Grande do Sul. Disponível em:

http://www2.senado.leg.br/bdsf/bitstream/handle/id/70451/CE_RioGrandedoSul.pdf?sequenc $\mathrm{e}=4>$. Acesso em 05 set 2018

.Constituição do Estado do Rio Grande do Norte. Disponível em:

<https://www2.senado.leg.br/bdsf/bitstream/handle/id/70437/CE_RioGrandedoNorte.pdf?seq uence $=1>$. Acesso em 05 set 2018

.Constituição do Estado do Acre. Disponível em: <http://www.al.ac.leg.br/wpcontent/uploads/2014/10/constitui\%C3\%A7\%C3\%A3o_atualizada.pdf>. Acesso em 05 set 2018

Constituição do Estado de Alagoas. Disponível em

<https://sapl.al.al.leg.br/sapl_documentos/norma_juridica/2_texto_integral>. Acesso em 05 set 2018

.Constituição do Estado do Rio de Janeiro. Disponível em

$<$ http://alerjln1.alerj.rj.gov.br/constest.nsf/PageConsEst?OpenPage>. Acesso em 05 set 2018

.Constituição do Estado do Mato Grosso. Disponível em:

<http://www2.senado.leg.br/bdsf/bitstream/handle/id/70444/CE_MatoGrosso.pdf?sequence= 11>. Acesso em 05 set 2018

Rev. de Direito Sociais e Políticas Públicas | e-ISSN: 2525-9881 | Goiânia| v. 5 | n. 1 | p. 119-140| Jan/Jun. 2019 
.Constituição do Estado de Amazonas. Disponível em

http://www2.senado.leg.br/bdsf/bitstream/handle/id/70430/CE_Amazonas.pdf?sequence=14> . Acesso em 05 set 2018

Constituição do Estado de Minas Gerais. Disponível em

https://www.almg.gov.br/export/sites/default/consulte/legislacao/Downloads/pdfs/Constituica oEstadual.pdf>. Acesso em 05 set 2018

. Constituição do Estado de Rondonia. Disponível em

http://www.rondonia.ro.gov.br/sepog/institucional/legislacao/organizacao/constituicaoestadual/>. Acesso em 05 set 2018

Constituição do Estado da Bahia. Disponível em

http://www2.senado.leg.br/bdsf/bitstream/handle/id/70433/CE_Bahia.pdf?sequence=13>. . Acesso em 05 set 2018

Constituição do Estado do Pará. Disponível em

http://pa.gov.br/downloads/ConstituicaodoParaateaEC48.pdf> . Acesso em 05 set 2018

Constituição do Estado de Roraima. Disponível em

http://www2.senado.leg.br/bdsf/bitstream/handle/id/70439/CE_Roraima.pdf?sequence=11>. Acesso em 05 set 2018

Constituição do Estado de Ceará. Disponível em

http://www2.senado.leg.br/bdsf/bitstream/handle/id/70432/CE_Ceara.pdf?sequence=1 >.

Acesso em 05 set 2018

Constituição do Estado da Paraíba. Disponível em http://tce.pb.gov.br/wp-

content/uploads/2013/09/constituicaoestadualpb.pdf >. Acesso em 05 set 2018

Constituição do Estado de Santa Catarina. Disponível em

http://www.alesc.sc.gov.br/legislacao>. Acesso em 05 set 2018

Constituição do Estado do Paraná. Disponível em

http://www.alep.pr.gov.br/system/files/corpo/constituic_parana.pdf>. Acesso em 05 set 2018

Constituição do Estado de São Paulo. Disponível em

http://www.legislacao.sp.gov.br/legislacao/dg280202.nsf/a2dc3f553380ee0f83256cfb005014

63/46e2576658b1c52903256d63004f305a?OpenDocument>. Acesso em 05 set 2018

Rev. de Direito Sociais e Políticas Públicas | e-ISSN: 2525-9881 | Goiânia| v. 5 | n. 1 | p. 119-140| Jan/Jun. 2019 
. Constituição do Estado do Espírito Santo. Disponível em

http://www.al.es.gov.br/appdata/anexos_internet/downloads/c_est.pdf. Acesso em 05 set 2018

Constituição do Estado de Pernambuco. Disponível em

$<$ http://legis.alepe.pe.gov.br/arquivoTexto.aspx?tiponorma=12\&numero=1989\&complement $\mathrm{o}=0 \&$ ano $=1989 \&$ tipo $=\& u r l=>$. Acesso em 05 set 2018

Constituição do Estado de Sergipe . Disponível em <https://al.se.leg.br/wpcontent/uploads/2016/03/constituicao_do_estado_de_sergipe_2007.pdf >. Acesso em 05 set 2018

Constituição do Estado de Goiás. Disponível em:

<http://www.gabinetecivil.goias.gov.br/constituicoes/constituicao_1988.htm>. Acesso em 05 set 2018

Constituição do Estado do Piauí. Disponível em:

http://www.cge.pi.gov.br/legis/legislacao/constituicao-do-estado-do-piaui-2013.pdf>. Acesso em 05 set 2018

. Constituição do Estado do Tocantins. Disponível em:

http://www2.senado.leg.br/bdsf/bitstream/handle/id/70431/CE_Tocantins.pdf?sequence=11>. Acesso em 05 set 2018

CHAVES, Andre Santos; MARTINI, Sandra Regina. Necessidade de confiança na jurisdição constucional para efetivação do direito à saúde. Disponível em: < http://www.scielo.br/pdf/inter/v19n1/1518-7012-inter-19-01-0077.pdf>. Acesso em 10 ago 2018

DORIGON, Natalia Alberton. 2018. Universidade do Extremo Sul Catarinense. As políticas públicas e o direito das pessoas com deficiência à Educação. Disponível em: http://periodicos.unesc.net/AnaisDirH/article/view/4638/4237. Acesso em 15 abr 2018 COTOMACCI, Giovana. Lazer: Direito e acessibilidade das pessoas com deficiência ou necessidades especiais. 2007. Universidade Estadual de Campinas. Disponível em file://C:/Users/Tiago/Downloads/CotomacciGiovana_TCC.pdf. Acesso em: 05 agosto 2018. FREITAS, Maria Nivalda de Carvalho; MARQUES, Antônio Luiz. Satisfação das pessoas com deficiência no trabalho. In: CARVALHO-FREITAS, Maria Nivalda de; MARQUES, 
Antônio Luiz (Orgs.). Trabalho e pessoas com deficiência: pesquisa, práticas e instrumentos de diagnóstico. Curitiba: Juruá, 2009

LARAIA, Maria Ivone Fortunato. A pessoa com deficiência e o direito ao trabalho.

Pontífica Universidade Católica de São Paulo. 2009. Disponível em:

https://tede.pucsp.br/bitstream/handle/8878/1/Maria\%20Ivone\%20Fortunato\%20Laraia.pdf. Acesso em 05 ago 2018.

MARTA, Taís Nader; ABUJAMRA, Ana Carolina Peduti, 2010. Pessoa com deficiência e o direito ao adequado tratamento de saúde. Disponível em

https://www.publicacoes.uniceub.br/jus/article/viewFile/1058/1153 acesso em 15 abr 2019

RESENDE, Marlene das Graças de. A inclusão de pessoas com deficiência no mercado de trabalho. Disponível em: <http://www.inclusive.org.br/wp-

content/uploads/A_inclus_de_pessoas.pdf>. Acesso em: 15 ago 2018

SARLET, Ingo Wolfgang. Dignidade da Pessoa Humana e Direitos Fundamentais na

Constituição Federal de 1988. 5. ed. Porto Alegre: Livraria do Advogado, 2007.

SASSAKI, Romeu Kazumi. Inclusão: o paradigma do século 21. Inclusão: Revista da

Educação Especial, p. 19- 23, out. 2005. Disponível em: <http: //portal.mec.gov.br/

seesp/arquivos/ pdf/ revistainclusao1.pdf>. Acesso em: 25 jul.2009.

TOMAZINI, M. E. A. Trabalho e deficiência: uma questão a ser repensada. Palestra ministrada no II Seminário Paranaense de Educação Especial. [Tema: Educação, Trabalho e Cidadania], realizado em Curitiba, em 5-8 de novembro de 1996.

VIEIRA, Reginal de Souza. A cidadania na república participativa: Pressupostos para a articulação de um novo paradigma jurídico e político para os conselhos de saúde.

Disponível em:

https://repositorio.ufsc.br/bitstream/handle/123456789/107508/319593.pdf?sequence=1.

Acesso em: 05 ago 2018

Rev. de Direito Sociais e Políticas Públicas | e-ISSN: 2525-9881 | Goiânia| v. 5 | n. 1 | p. 119-140| Jan/Jun. 2019 